\title{
THE BRACKISH WATER MOSQUITOES OF PUERTO RICO ${ }^{1}$
}

\author{
By GeORge S. TUluoch, Associate Entomologist, \\ Division of Inseets Affecting Man and Animals, \\ Bureau of Entomology and Plant Quarantine
}

The purpose of this paper is to report on studies concerning the distribution in Puerto Rico of certain species of mosquitoes which breed in brackish waters. These species may be divided into two groups. The first includes those forms which were found in both fresh and brackish waters and the second, those forms found only in brackish waters. Although the tolerance or preference of certain mosquitoes for water containing vaious quantities of salt has been recognized for many years, little attention has been directed to a study of the various species in relation to the salt content of their breeding media. The data on this subject presented here are based on observations made in Puerto Rico during 1935-36.

The salts responsible for the brackish condition of certain mosquito breeding waters in Puerto Rico are derived either from the soil or from the ocean. The salts in the soil have been deposited as a result of the decomposition of organic or inorganic materials, and in certain parts of the coastal plain-relatively large amounts are present. It is probable that at one time soil salts were rather generally distributed throughout the entire coastal plain. In regions having heavy rainfall and good drainage, leaching has proceeded to the extent that the soil is suitable for agricultural purposes. In dry, poorly drained areas, such as are found in portions of the southern coastal plain, the leaching process has proceeded at a much slower rate with the result that the soil is unfit for agricultural purposes. In these areas rain or waste irrigation waters accumulate in natural or artificial depressions, salts pass into solution, and a brackish pool suitable for the development of certain mosquitoes results. It is, therefore, not uncommon in Puerto Rico to find the salt-marsh mosquito, Aedes sollicitans (Walk.) developing in pools which may be many miles away from the ocean. The area of this habitat is increased during the rainy season and decreased during

1 These investigations were carried on with special funds available to the Bureau of Entomology and Plant Quarantine of the U. S. Department of Agriculture for studies on insects of Puerto Rico. They were under the technical direction of the Division of Insects Affecting $\mathrm{A}$ Ian and Animals, and conducted in cooperation with the Federal Fxperimont Station at Mayaguez, where hendquarters for the investigations were located. 
the dry season. The concentration of the salts in the pools is increased by evaporation and decreased by the addition of water.

In certain regions along the seacoast where the slope is gradual, tidal swamps are present. Brackish water areas are produced by the mixing of ocean water with drainage, rain, and waste irrigation waters, and if other conditions are favorable, breeding of mosquitoes takes place. A similar condition is produced in the rivers at certain seasons. The topograhy of Puerto Rico is such that the rivers arising in the central mountainous regions must traverse a flat coastal plain before reaching the ocean. The flow of the rivers is retarded by the loss of grade in the coastal plain and by sand bars thrown across the river mouths by tides. During the rainy season the rivers are able to maintain channels through the sand bars, but during the dry season the sandbars cause the river waters to become impounded in their own courses. During high tides and storms, waves pass over the sandbars into the impounded fresh waters, causing them to become brackish. In the shallow margins of these impounded brackish areas the development of mosquitoes takes place.

The brackish condition of the mosquito-breeding areas is caused principally by chlorides. The concentration of chlorides, or, rather, the total halogen expressed as chlorine, serves as an indication of the brackish condition of a pool. In pools which receive their salts from the ocean the relation between the halides and the total salinity is definite and is based on the following formula.

\section{Salinity $=0.030+1.8050$ Chlorine $^{1}$}

In pools which receive their salts from other sources the halide concentration is not a direct index of the salinity but it serves, nevertheless, as an indication of the brackish condition. Accordingly a quantitative study of the halides was made in pools containing mosquitoes. The halide concentration was determined by volumetric titration and is expressed as parts of chlorine per 100,000 parts of sample.

The following 12 species of mosquitoes were taken in brackish waters in Puerto Rico: Aedes sollicitans (Walk.), A. taeniorhynchus (Wied.), Anopheles albimanus Wied., A. crucians Wied., A. grabhamii Theob., Culex atratus Theob., C. bahamensis Dyar and Knab, C. habilitator Dyar and Knab, C. inhibitator Dyar and Knab, C. nigripalpus Theob., and Psorophora pygmaea (Theob.), and Urano-

\footnotetext{
${ }^{1}$ Knudsen, M. 1901. Hydrographical Tables. Copenhagen.
} 
taenia sp. Only three of these, Anopheles crucians, Aedes sollicitans, and Culex bahamensis, were found to be restricted to this habitat, the remaining nine being taken at other times in waters free of chlorides.

It was possible from quantitative field tests to establish provisional chlorine ranges for nine of the species (Table 1). Culex habilitator and a species of Uranotaenia ${ }^{1}$ were found in fresh waters and in brackish waters containing up to 210 parts of chlorine. Culex nigripalpus, Psorophora pygmaea, Culex inhibitator, Anopheles albimanus, and Anopheles grabhamii have greater ranges, which suggests a greater tolerance for salts. A distinct preference for salts is exhibited by Culex bahamensis and Aedes sollicitans.

Table 1.-Provisional Chlorine Ranges of Waters in Which Various

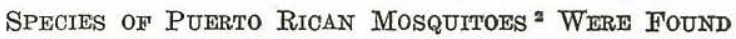

Species
Culex habilitator
Uranotaenia sp.
Culex nigripalpus
Psorophora pygmaea
Culex inhibitator
Anopheles albimanus
A. grabhamii
Culex bahamensis
Aedes sollicitans

Parts chlorine per 100,000 parts of sample 0-185

$0-210$

$0-540$

$0-765$

$0-770$

0-950

0-950

195-900

370-940
Number of collections

8

95

20

3

30

111

8

13

11

${ }^{1}$ It is possible that two species of Uranotaenia are involved.

${ }^{2}$ Sea water contains approximately 2,000 parts of chlorine per 100,000.

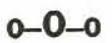

